\title{
USO DE SIG NA ANÁLISE DOS RECURSOS HÍDRICOS NO MUNICÍPIO DE CAICÓ (RN)
}

Luzia Carla de Medeiros ${ }^{\mathbf{1}}$, Jânio Carlos Fernandes Guedes ${ }^{\mathbf{1}}$, Alisson Medeiros de Oliveira ${ }^{\mathbf{1}}$, Diógenes Félix da Silva Costa ${ }^{\mathbf{1 , 2}}$

(1 - Universidade Federal do Rio Grande do Norte - UFRN/Grupo de Pesquisa em Geoecologia e Biogeografia Tropical - TRÓPIKOS; luzia.labesa@yahoo.com.br, janio.labesa@yahoo.com.br, alissongeoliveira@gmail.com, 2 - Professor Adjunto do Departamento de Geografia e do Programa de Pós-Graduação e Pesquisa em Geografia da UFRN, Centro de Ensino Superior do Seridó, Campus de Caicó/RN, 59.300-000, Email: dfscosta@ceres.ufrn.br).

RESUMO: A demanda pelos recursos hídricos é constante no semiárido, devido ao aumento populacional e ao desenvolvimento econômico. Com isso, o presente estudo teve como objetivo analisar a redução da área dos reservatórios em um período de estiagem no semiárido. O trabalho foi desenvolvido no município de Caicó/RN, caracterizado por apresentar altas taxas de evaporação em seus reservatórios. Os mapas temáticos foram elaborados em ambiente de SIG. Ao final do mapeamento, os reservatórios foram classificados de acordo com o tamanho de sua área (hectare), e divididos em cinco classes. Verificou-se que o longo do período de estiagem e os usos múltiplos dos recursos hídricos colaboraram para que houvesse perda significativa na área dos reservatórios, registrando-se o desaparecimento de 57 reservatórios. Por isso, a importância de estudos como este, que proporcionem um maior conhecimento da região, mostrando, também, a influência nos corpos hídricos, para que haja melhor gestão desses recursos.

Palavras-Chave: Semiárido; Reservatórios; Sensoriamento Remoto.

\section{USE OF GIS IN THE ANALYSIS OF WATER RESOURCES IN THE MUNICIPALITY OF CAICÓ (BRAZIL)}

\footnotetext{
Artigo recebido para publicação em 22 de Novembro de 2015
} Artigo aprovado para publicação em 10 de Dezembro de 2016 
ABSTRACT: The demand for water resources is constant in the semi-arid area, due to the population increase and economic development. So the present study aimed to analyze the reduction of the area of reservoirs in a period of drought in the semi-arid region. The work was developed in the city of Caicó/RN, characterized by high rates of evaporation in its reservoirs. The thematic maps were prepared in GIS environment. At the end of the mapping, the reservoirs were classified according to the size of their areas (hectare), and divided into five classes. It was found that during the dry season and the multiple uses of water resources contributed to significant loss in the area of reservoirs, registering the disappearance of 57 reservoirs. Therefore, the importance of studies such as this one, which provide a greater knowledge of the region, showing also the influence on water bodies for better management of these resources.

Keywords: Semi-arid; Reservoirs; Remote Sensing.

\section{USO DEL SIG EN EL ANÁLISIS DE LOS RECURSOS DE AGUA EN EL MUNICIPIO CAICO (BRASIL)}

RESUMEN: La demanda de agua es constante en la región semiárida, debido al crecimiento de la población y el desarrollo económico. Por lo tanto, este estudio tuvo como objetivo analizar la reducción de la zona del embalse en un período de sequía en la región semiárida. El trabajo se desarrolló en la ciudad de Caicó / RN, caracterizado por el hecho de que las altas tasas de evaporación en sus depósitos. Los mapas temáticos fueron preparados en un ambiente SIG. Al final de la cartografía, los depósitos se clasificaron según el tamaño de su área (ha), y se dividieron en cinco clases. Se encontró que durante la estación seca y los múltiples usos de los recursos hídricos han contribuido a que hubo una pérdida significativa en la zona de los embalses, el registro de la desaparición de 57 embalses. Por lo tanto, la importancia de estudios como éste, que proporcionan una mejor comprensión de la región, que muestra también la influencia de las masas de agua, por lo que hay una mejor gestión de estos recursos.

Palabras clave: Semiárido; Depósitos; Detección remota.

\section{Introdução}


A demanda pelos recursos naturais vem aumentando cotidianamente, principalmente pelos recursos hídricos, os fatores que tem contribuído para isso é o aumento populacional e o desenvolvimento econômico (GONDIM-FILHO et al., 2004). A água é considerada insumo básico da sobrevivência de todas as espécies e um indicador do desenvolvimento de uma região. Sendo necessária uma atenção especial no seu manejo, visando sua conservação em qualidade e quantidade. A gestão dos recursos hídricos refere-se então aos procedimentos relativos à tentativa de equacionar e otimizar os seus usos (SETTI et al., 2001).

A construção de reservatórios hidrológicos têm sido uma das alternativas para armazenar água provinda das precipitações, essas por sua vez variando de local pra local. A construção desses reservatórios data de milhares de anos e tinham como finalidade inicial armazenar água para abastecimento ou irrigação. Dessa forma, com o passar dos tempos, esses ecossistemas tornaram-se grandes empreendimentos, sendo utilizados para inúmeros e múltiplos fins (TUNDISI; MATSUMURA-TUNDISI, 2008) como: a agricultura, o abastecimento público de água em ambientes urbanos e as indústrias com grande consumo deste recurso (QUEIROZ; OLIVEIRA, 2013).

No Brasil, as represas e reservatórios são construídos principalmente pelo represamento de rios para atender as necessidades da população, como abastecimento de água, regularização de cursos, obtenção de energia elétrica, irrigação, navegação e recreação (ESTEVES, 1998; ESTEVES, 2011).

Em regiões semiáridas como o Nordeste brasileiro, onde as condições climáticas caracterizam-se pela elevada evaporação em todos os meses do ano e por uma quantidade de chuvas menor que os totais evaporados, a construção de reservatórios constitui-se uma das medidas para combater as consequências negativas das adversas condições ambientais existentes, visando o aproveitamento em diversos usos, inclusive o abastecimento (BRASIL, 2005).

Segundo Malvezzi (2007), o semiárido brasileiro abrange uma área de 912 mil quilômetros quadrados, possuindo pluviosidade média de $750 \mathrm{~mm} . \mathrm{ano}^{-1}$. A formação do substrato rochoso possui $70 \%$ de rochas cristalinas, tem solos rasos, taxa de evaporação maior que a chuva precipitada e variação das chuvas no tempo e no espaço são algumas das características que fazem com que exista o déficit hídrico, mas isso não significa dizer que há uma falta d'água. 
Outros aspectos importantes que qualificam o semiárido como unidade fundamental de estudo e de gestão é a possibilidade de integrar soluções para o desenvolvimento local e regional no tocante aos recursos naturais (TUNDISI; MATSUMURA-TUNDISI, 1995).

Com isso, o semiárido nordestino brasileiro configura um cenário crítico no que se refere à questão hídrica, necessitando de subsídios para implantação de uma gestão visando à racionalização do uso de suas águas com base nessa realidade (FONTES et al., 2003).

Reservatórios hidrológicos no semiárido brasileiro incluem lagos rasos (MALTCHIK et al., 1999), reservatórios artificiais (BARBOSA, 2002) e intermitentes, córregos e rios (exceto para o perene como o São Francisco e os rios artificialmente regulados) (MALTCHIK; MEDEIROS, 2006), estes sistemas são distintos na paisagem semiárida e compreende uma série de sistemas de funcionamento associado, como um mosaico em constante mudança, ou seja, períodos secos e úmidos (BARBOSA et al., 2012).

Diante dos dados apresentados percebe-se a relevância de estudos para minimizar as perdas d'água nos corpos hídricos, dentre essas, destaca-se o entendimento da evaporação, essa por sua vez como sendo uma variável crítica dentro do balanço hídrico de regiões semiáridas, chegando a representar $92 \%$ do volume precipitado anual médio. Estudos realizados no semiárido estimam que cerca de $40 \%$ das águas acumuladas em reservatórios se perde com a evaporação (Suassuna, 2012). Segundo este autor, a evaporação no semiárido tem papel fundamental no dimensionamento e manejo de obras hídricas, que deve ser minuciosamente investigado para subsidiar ações de planejamento e gerenciamento buscando melhor aproveitamento das águas reservadas.

Recentemente, os SIGs (Sistema de Informações Geográficas) têm sido amplamente adotados como uma ferramenta essencial para o uso eficaz e exibição de informação geográfica sobre os recursos hídricos. Além disso, o inventário destes recursos através desta abordagem será também extremamente útil no desenvolvimento de políticas de água adequados para a nível de região (VAN TY et al., 2009). Onde muitas propriedades de bacias hidrográficas relevantes para estudos de sedimentação podem ser estimadas utilizando um banco de dados SIG para associar dados de topografia, clima, solos e cobertura do solo (MIXON et al., 2008).

Considerando a necessidade de ações de planejamento do uso dos recursos no semiárido, principalmente nas áreas em processo de desertificação, o presente trabalho teve como objetivo analisar a redução da área dos reservatórios ao longo de um período de 
estiagem sazonal (seca) em um município inserido na categoria de Área Afetada por Processos de Desertificação (Classe Muito Grave) (SANTANA, 2007).

Considerando-se que este período de estiagem pelo qual a região Nordeste vem passando (teve início a partir de 2010), este trabalho apresenta uma análise da redução da bacia hidráulica dos reservatórios a partir do último ano com pluviosidade anual acima de 1.000 mm.ano ${ }^{-1}$ (2009). Nesse sentido, realizou-se uma análise comparativa em SIG (Sitema de Informação Geográfica) com a perda de área entre 2009 e 2012 (máximo de estiagem regional).

\section{MATERIAIS E MÉTODOS}

\section{1 Área de estudo}

A área de estudo está situada a 40 km do Núcleo de Desertificação do Seridó (RN), compreendendo todo o município de Caicó, o qual está classificado como Área Afetada por Processos de Desertificação (Classe Muito Grave) (SANTANA, 2007).

Este município localiza-se na Microrregião do Seridó Ocidental do Estado do Rio Grande do Norte $\left(6^{\circ} 27^{\prime} 37,56^{\prime \prime} \mathrm{S}\right.$ e $\left.37^{\circ} 5^{\prime} 54,51^{\prime \prime O}\right)$, com aproximadamente $1.228,576 \mathrm{~km}^{2}$ (Figura 1). O clima regional é classificado como BSh (classificação de Köppen): tropical semiárido quente e seco, com precipitação pluviométrica média anual baixa $\left(<800 \mathrm{~mm} \cdot \mathrm{ano}^{-1}\right)$ e uma estação acentuadamente seca, apresentando um dos climas mais quentes e secos do Nordeste brasileiro, com temperatura média anual acima de $27,4^{\circ} \mathrm{C}$ (MENDONÇA e DANNIOLIVEIRA, 2007, 206 p.). 


\begin{tabular}{|c|c|c|}
\hline & $\begin{array}{c}\text { GEOAMBIENTE ON-LINE } \\
\text { Revista Eletrônica do Curso de Geografia - UFG/REJ } \\
\text { Graduação e Pós-Graduaçăo em Geografia } \\
\text { http://revistas.ufg.br/index.php/geoambiente/index } \\
\text { Apoio: PRPG/PROAPUPEC }\end{array}$ & $\begin{array}{l}\text { NTE } \\
79-986\end{array}$ \\
\hline & Jataí-GO | n.27 | Jul-Dez/2016 & \\
\hline
\end{tabular}

Figura 1: Mapa de localização do municipio de Caicó/RN

Figure 1: Location map of the municipality of Caico / RN
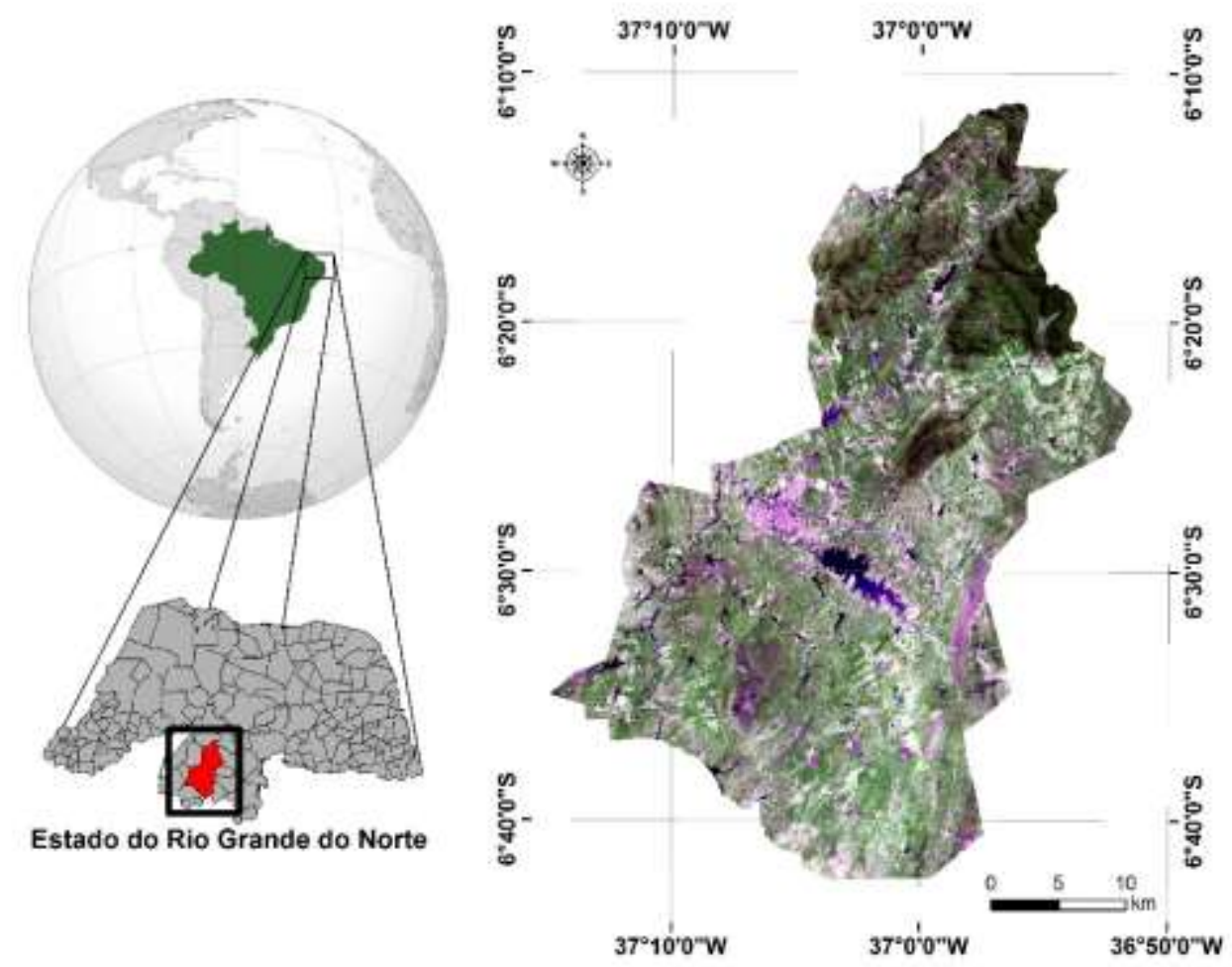

Fonte: Acervo dos autores

\subsection{Procedimentos metodológicos}

As etapas metodológicas para o mapeamento hidrológico foram divididas em: 1) levantamento bibliográfico e cartográfico prévio da área de estudo; 2) processamento digital das imagens, envolvendo técnicas de realce de contraste das imagens orbitais, fusão entre as bandas multiespectrais, composições coloridas no sistema de cores RGB (Red-Green-Blue) e mosaico das diferentes cenas processadas; 3) classificação e quantificação da área das diferentes imagens de satélites da região em estudo de períodos distintos (seca e chuvoso) através de mapas temáticos em escala de 1:10.000 (a partir da análise espectral, tonalidades e texturas das imagens), realizadas com base nas categorias descritas pelo Manual Técnico de Uso da Terra do IBGE (2006). Por fim, foi realizada a avaliação de campo para confirmação das classes identificadas nas imagens.

A partir da análise dos dados pluviométricos mensais da região e com base no índice de cobertura de nuvens, foram selecionadas imagens de satélites representando o último ano com pluviosidade anual acima de $1.000 \mathrm{~mm}^{\mathrm{ano}}{ }^{-1}$ (2009) e o ano de 2012, onde verificou o 
máximo de estiagem regional. Com vistas em ter uma análise mais precisa sobre a redução de área dos reservatórios, realizou-se também uma análise intraanual comparando-se 02 períodos no ano de 2012 (final do período chuvoso e o máximo estiagem anual). Os dados de precipitação mensais utilizados no trabalho foram obtidos na Estação Climatológica de Caicó/RN (INPE), localizada no Campus da Universidade Federal do Rio Grande do Norte UFRN.

Com base nestes dados para o intervalo 2009 a 2012, assim como a partir do índice de cobertura de nuvens informado pelo INPE ao se solicitar as imagens, todo o material cartográfico foi elaborado a partir da composição de bandas dos seguintes satélites: CBERS (sensor: CCD, órbita 148, ponto 107, de 15/11/2009) e Resource-Sat (sensor: LISS3, órbita 337, ponto 081, de 07/2012 e de 10/2012). Ambas as imagens possuem resolução espacial de 20 metros, nas quais foram aplicadas técnicas de análise espectral, a partir das tonalidades e texturas das imagens, para obter-se uma maior riqueza de detalhes dos alvos. Estas imagens foram disponibilizadas gratuitamente pelo Instituto Nacional de Pesquisas Espaciais - INPE, onde todo o processamento digital foi realizado com o auxílio do software ENVI v. 4.7 $\left(\mathrm{ENVI}^{\circledR}\right)$, obtendo-se imagens resultantes em falsa cor $(\mathrm{R} 3 \mathrm{G} 4 \mathrm{~B} 2)$.

Para atingir a precisão desejada, as imagens foram georreferenciadas na grade de coordenadas UTM (Universal Transversa de Mercartor), iniciando-se pelas cartas topográficas (em formato digital) da SUDENE (SB-24-Z-B-I Caicó), em escala de 1:100.000, a partir do Datum Córrego Alegre. Logo em seguida, após se concluir este processo, o Datum das cartas foi modificado para SIRGAS 2000, Zona 24 S.

Após o georreferenciamento das imagens, as cenas foram mosaicadas em ambiente de Sistema de Informação Geográfica (SIG), bem como todo o processo de manipulação e integração dos dados espaciais. Em seguida, procedeu-se com a delimitação da bacia hidráulica dos reservatórios através da vetorização manual, onde toda a elaboração e layout final dos mapas temáticos foi realizadas com auxílio do software ArcGIS 10 (versão acadêmica - $\operatorname{ESRI}^{(}$). O software Excel (Microsoft Office ${ }^{\odot}$ ) também foi utilizado para a tabulação e armazenamento dos metadados.

\section{RESULTADOS E DISCUSSÕES}

A partir dos dados meteorológicos, registrou-se o maior índice pluviométrico dos últimos 5 anos (2009-2014), com um total acumulado de $1.315,7 \mathrm{~mm} . \mathrm{ano}^{-1}$, a partir do qual teve início o atual período de estiagem sazonal na região Nordeste do Brasil. Por sua vez, o 


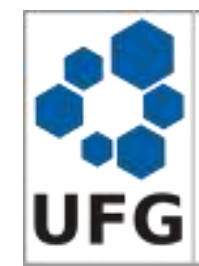

\section{GEOAMBIENTE ON-LINE \\ Revista Eletrônica do Curso de Geografia - UFG/REJ \\ Graduação e Pós-Graduaçăo em Geografia \\ http://revistas.ufg.br/index.php/geoambiente/index \\ Apoio: PRPG/PROAPUPEC \\ Jataí-GO | n.27 | Jul-Dez/2016}

:GEO

¿AMBIENTE

ISSN 1679-9860

ano de 2012 registrou um total de $200,6 \mathrm{~mm}$. ano $^{-1}$, representando o menor valor acumulado de precipitação durante todo o período de estiagem (máximo de estiagem regional). Estes dados foram relacionados com o total de reservatórios mapeados nas imagens dos diferentes anos (2009 e 2012), verificando-se uma redução acentuada do número total de reservatórios em função da estiagem (Figura 2).

Figura 2: Pluviosidade média anual do município de Caicó/RN, dos anos 2009 a 2012.

Figure 2: Average annual rainfall in the city of Caico / RN, the years 2009-2012.



A imagem de novembro de 2009, a qual evidencia o ano com maior pluviosidade no município de Caicó/RN, mostrou um número total de 427 reservatórios estando distribuídos em cinco classes: de 0,3-12,9 ha (371 reservatórios); 12,9-58,5 ha (51 reservatórios); 58,5173,5 ha (03 reservatórios); 173,5-315,6 ha (01 reservatórios) e de 315,6-1.092,4 ha (01 reservatórios) (Tabela 1 e Figura 3).

Tabela 1: Número de reservatórios dividido por classe de área em hectare (ano de 2009).

Table 1: Number of reservoirs divided by hectare in area class (2009).

\begin{tabular}{c|c}
\hline Reservatórios & Área (ha) \\
\hline 371 & $0,3-12,9$ \\
\hline 51 & $12,9-58,5$ \\
\hline 03 & $58,5-173,5$ \\
\hline 01 & $173,5-315,6$ \\
\hline 01 & $315,6-1.092,4$ \\
\hline
\end{tabular}

Fonte: Acervo dos autores 


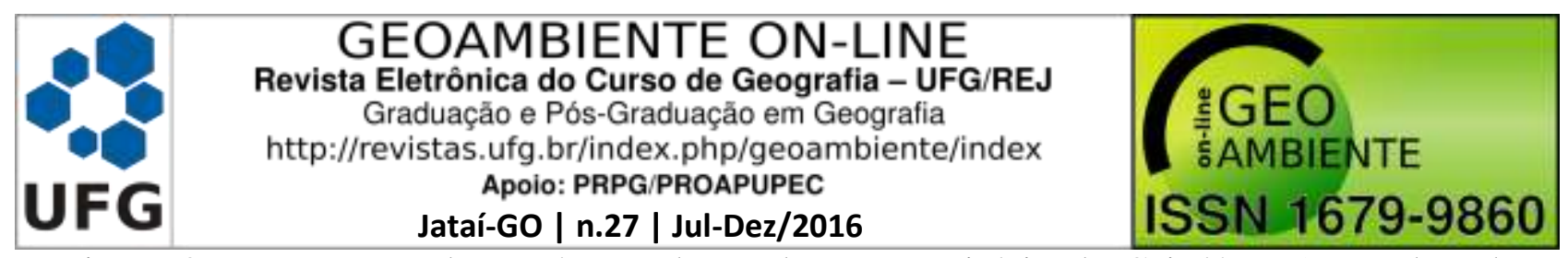

Figura 3: Mapa contendo o número de açudes no município de Caicó/RN (novembro de 2009).

Figure 3: Map containing the number of ponds in the city of Caico / RN (November 2009).

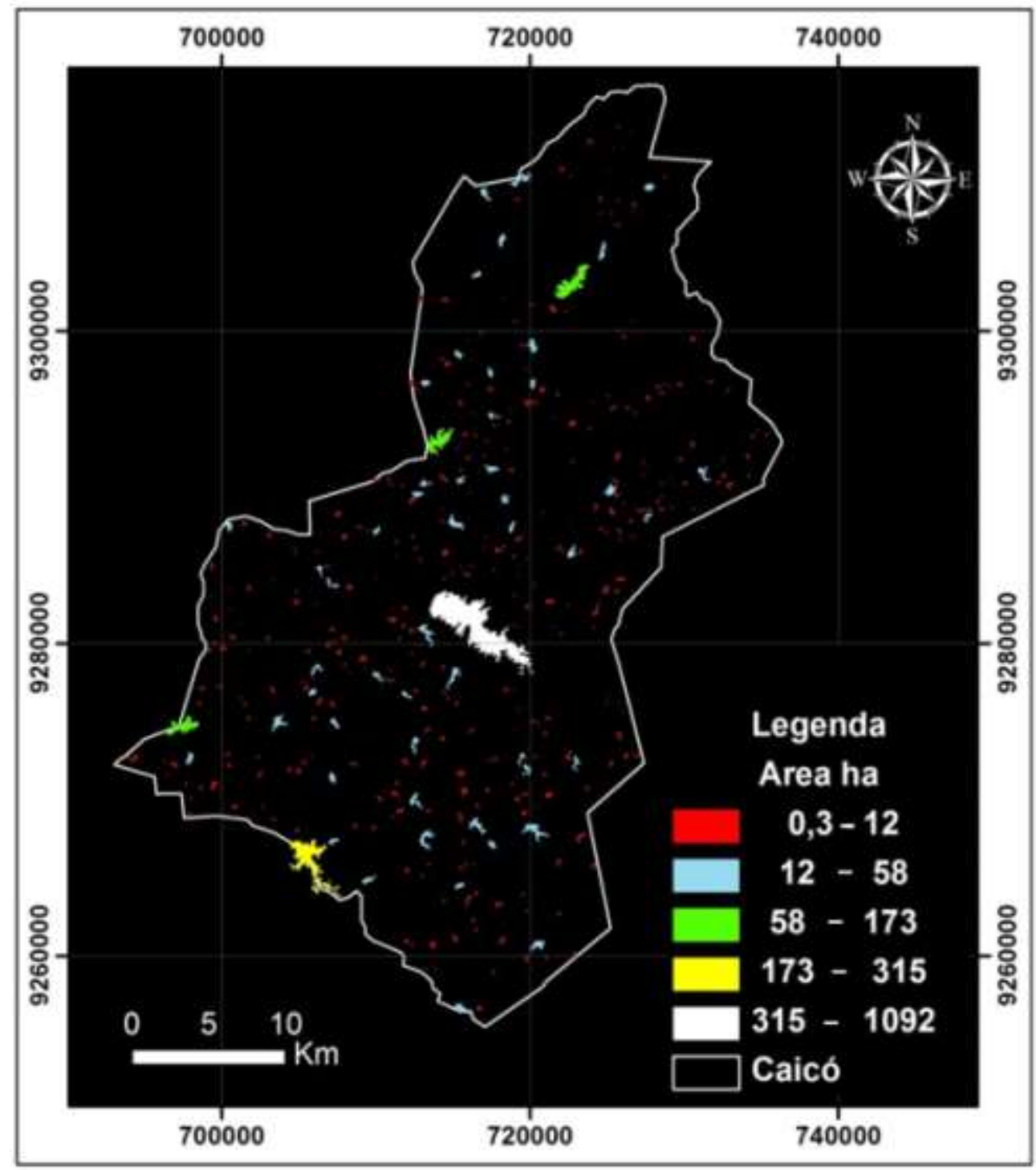

Fonte: Acervo dos autores

A partir da imagem do mês de julho de 2012, foi possível mapear um número total de 193 reservatórios, distribuídos da seguinte forma: de 1-5 ha (152 reservatórios); de 5-14 ha (25 reservatórios); 14-27 ha (11 reservatórios); 27-189 ha (04 reservatórios) e de 189-804 ha (01 reservatório), sendo este último representado pelo reservatório Itans, o qual abastece a cidade de Caicó/RN (Figura 4 e Tabela 2). 
¿ $\mathrm{GEO}$ ¿AMBIENTE ISSN $1679-9860$

Figura 4: Mapa contendo o número de reservatórios no município de Caicó/RN (julho de 2012).

Figure 4: Map containing the number of reservoirs in the city of Caico / RN (July 2012).

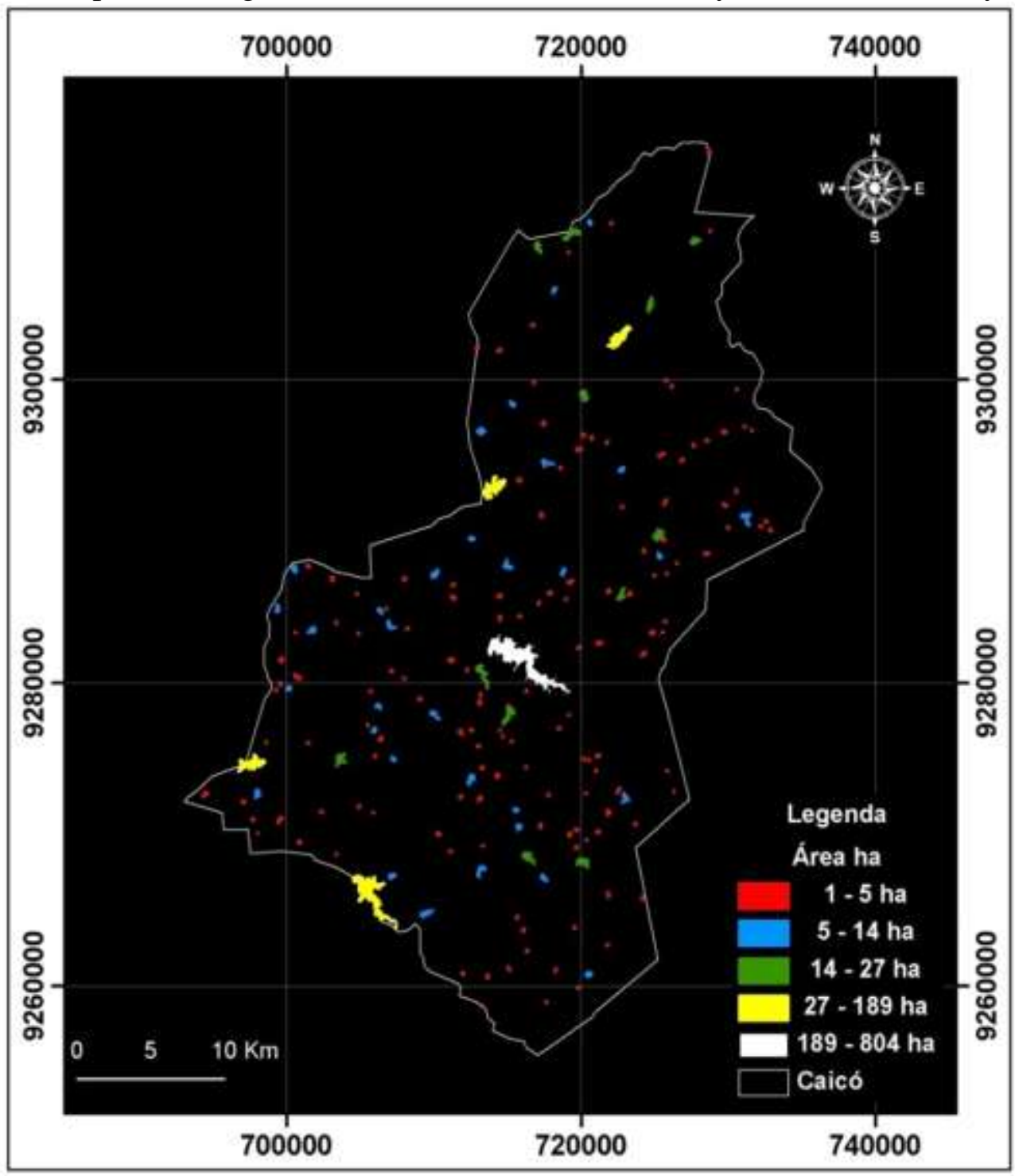

Fonte: Acervo dos autores

Tabela 2: Número de reservatórios divididos por classe de área em hectare (ano de 2012). Table 2: Number of reservoirs divided by hectare in area class (year 2012).

\begin{tabular}{c|c|c|c}
\hline $\begin{array}{c}\text { Reservatórios } \\
\text { (julho) }\end{array}$ & Área (ha) & $\begin{array}{c}\text { Reservatórios } \\
\text { (outubro) }\end{array}$ & Área (ha) \\
\hline 152 & $1-5$ & 104 & $0,1-2,7$ \\
\hline 25 & $5-14$ & 15 & $2,7-8,6$ \\
\hline 11 & $14-27$ & 12 & $8,6-21,1$ \\
\hline 04 & $27-189$ & 04 & $21,1-126,4$ \\
\hline 01 & $189-804$ & 01 & $126,4-664,5$ \\
\hline
\end{tabular}

Fonte: Acervo dos autores. 




Este total de reservatórios ainda apresenta uma redução no mês de outubro de 2012, mapeando-se apenas 136 reservatórios, nas seguintes classes: 0,1-2,7 ha (104 reservatórios); 2,7-8,6 ha (15 reservatórios); 8,6-21,1 ha (12 reservatórios); 21,1-126,4 ha (04 reservatórios) e de 126,4-664,5 ha (01 reservatório) (Tabela 2 e Figura 5).

Figura 5: Mapa contendo o número de reservatórios no município de Caicó/RN (outubro de 2012).

Figure 5: Map containing the number of reservoirs in the city of Caico / RN (October 2012).

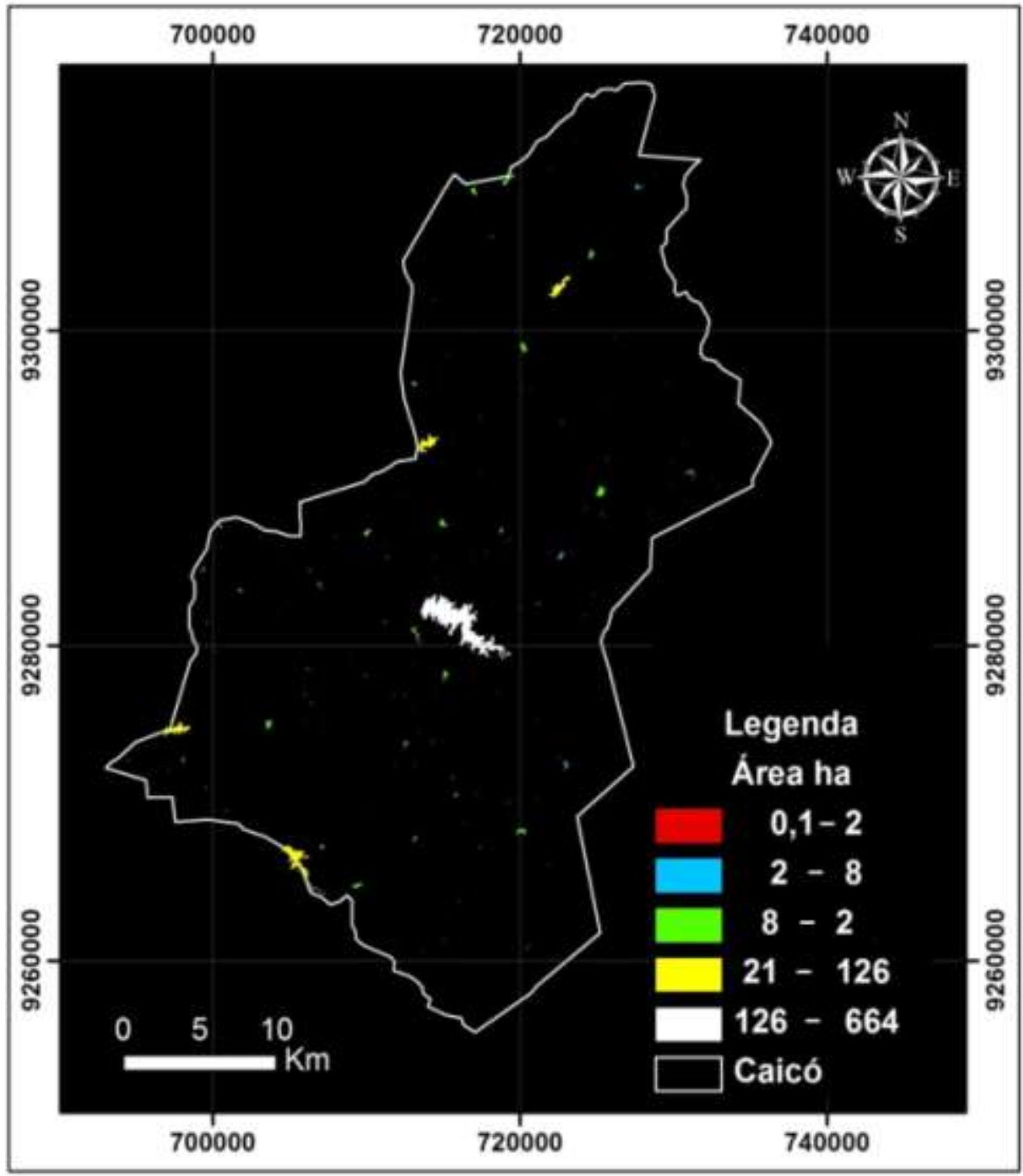

Fonte: Acervo dos autores

Os dados georreferenciados entre os anos de 2010 e 2012 demonstram que a área dos reservatórios diminuiu consideravelmente, como mostra os dados acima. A primeira imagem (Figura 2), referente ao período com maior pluviosidade (novembro de 2009), evidenciou 371 reservatórios com 0,3-12,9 hectares, enquanto que na segunda imagem, essa por sua vez, 
referente ao período de julho de 2012 (Figura 4) conforme a estiagem foi acentuando o número de reservatórios diminuiu para 151 de 1-5 hectares, e na terceira imagem de outubro de 2012 (Figura 5), esse número de reservatório foi para 104 com 1-2,7 hectares. Assim, notase o efeito da evapotranspiração, como também a utilização da água dos corpos hídricos para múltiplos usos, esses fatores, propiciaram para diminuição do espelho d'água dos reservatórios. Gondim-Filho et al. (2004) evidenciaram em seu estudo que tanto a demanda hídrica, as altas temperaturas, as taxas de evaporação, e as mudanças climáticas tornaram-se fatores ímpares que influenciam no nível d’água dos reservatórios.

A partir dessa abordagem, foi realizada uma análise do reservatório Itans, que abastece a cidade de Caicó/RN, com base nos dados multitemporais georreferenciadas e agrupados a partir os dados pluviométricos do município de Caicó/RN. Verificou-se que o reservatório apresentou uma redução significativa da área da bacia hidráulica, onde enquanto que no mês de novembro de 2009 o mesmo possuía uma área de 1.092 hectares (período chuvoso, segundo dados climatológicos), no mês de julho de 2012 (período de estiagem) essa área passou a ser de 804 hectares e, aproximadamente 3 meses depois para 664 hectares, ou seja uma perda de 39,2\% de sua área (Figura 6).

Segundo Medeiros et al. (2013), as condições climáticas e hidrológicas de determinada região são os principais parâmetros na estimativa das disponibilidades hídricas. Então, a compatibilidade entre a disponibilidade e a demanda hídrica, além dos parâmetros climáticos (precipitação, evaporação e evapotranspiração) e hidrológicos são fatores essenciais para o conhecimento de um corpo d'água, principalmente, para monitoramento hídrico de bacias hidráulicas, principalmente nos reservatórios utilizados para abastecimento público.

Um trabalho similar, porém mais amplo, foi desenvolvido por Martins et al. (2007), no qual os autores corroboram com a importância do mapeamento sistemático dos espelhos d'água como instrumento essencial o gerenciamento dos recursos hídricos em nível regional. A partir de imagens do satélite LANDSAT, os autores analisaram o total de espelho d'água existente em toda a região Nordeste do Brasil, mapeando apenas os reservatórios acima de 5 hectares. 


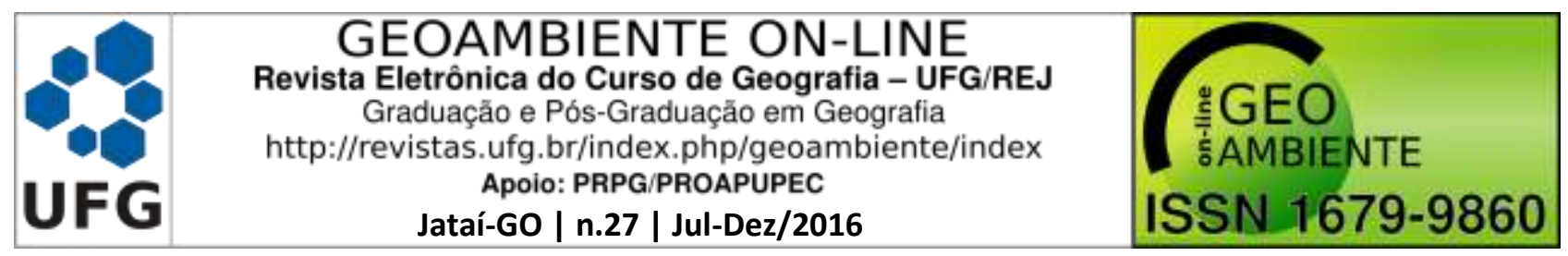

Figura 6: Mosaico de mapas em períodos distintos mostrando a perda em hectares devida o período de estiagem.

Figure 6: Mosaic maps at various times showing a loss due hectares in the dry season.

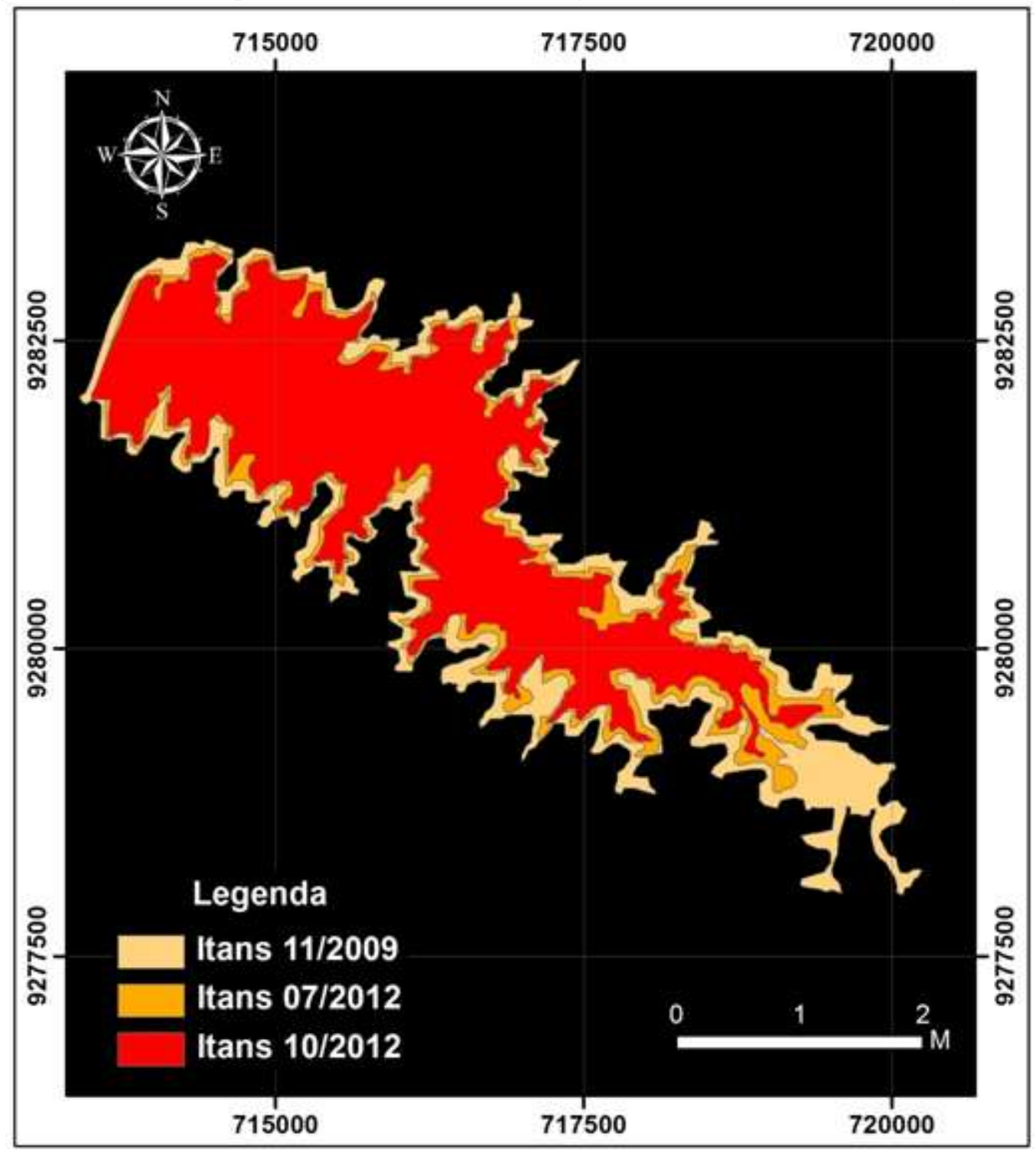

Fonte: Acervo dos autores.

\section{CONSIDERAÇÕES FINAIS}

- O presente estudo evidenciou a redução significativa de área de corpos hídricos (lagos reservatórios) no município de Caicó/RN, ocasionada pelas altas taxas de evaporação no longo período de estiagem do semiárido e os múltiplos usos das águas dos reservatórios hídricos.

- Tendo em vista o cenário atual, em que o uso predominante da água é para o abastecimento público, esta análise da disponibilidade hídrica mostra-se como uma ferramenta util para consulta do poder público. A partir deste, deverão ser tomadas 


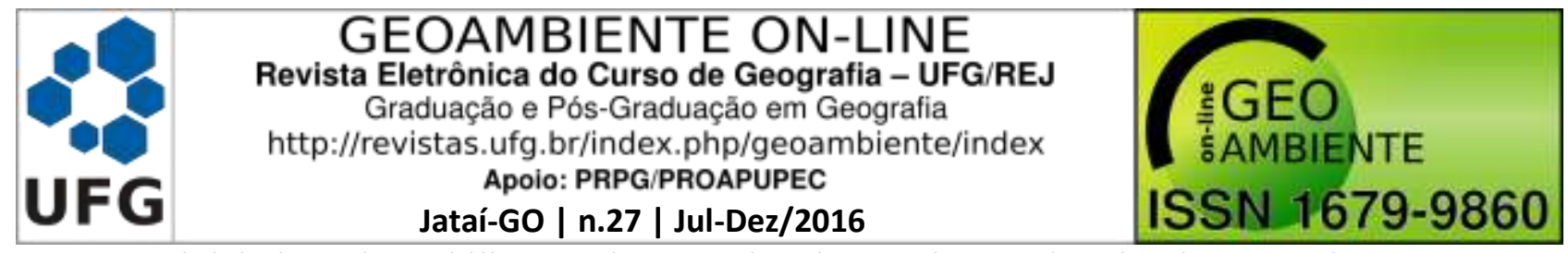

iniciativas de mobilização dos usuários d'água, buscando a implantação de ações que visem o manejo adequado da regulação hídrica nos períodos de estiagem.

- Estes dados também poderão subsidiar uma discussão mais ampla sobre as estratégias de gestão dos recursos hídricos no semiárido, em particular sobre a construção, manejo e conservação dos reservatórios. Dessa forma, algumas medidas mitigadoras devem ser planejadas tanto a nível local quanto regional, principalmente na área onde este estudo foi realizado.

\section{AGRADECIMENTOS}

Os autores agradecem ao Laboratório Multiusuário de Monitoramento Ambiental e ao Centro de Ensino Superior do Seridó (UFRN) pelo apoio logístico e instrumental nos trabalhos de campo e de gabinete, assim como a PROPESQ/UFRN, pelo apoio financeiro através do projeto "Dinâmica multitemporal da disponibilidade hídrica dos reservatórios do município de Caicó-RN (UFRN-PROPESQ ref. PVF11190-2014)”.

\section{REFERÊNCIAS BIBLIOGRÁFICAS}

BARBOSA, J. E. L. Dinâmica do fitoplâncton e condicionantes limnológicos nas escalas de tempo (nictemeral/sazonal) e de espaço (horizontal/vertical) no Açude Taperoá II: trópico semiárido nordestino. 2002. 201 f. Tese (Doutorado em Ciências Biológicas) - Universidade Federal da São Carlos, São Carlos, 2002.

BARBOSA, J. E. L.; MEDEIROS, E. S. F.; BRASIL, J.; CORDEIRO, R. S.; CRISPIM, M. C. B.; GONZAGA-SILVA, G. H. Aquatic systems in semi-arid Brazil: limnology and management Ecossistemas aquáticos do semi-árido brasileiro: aspectos limnológicos e manejo. Acta Limnologica Brasiliensia, v. 24, n. 1, p. 103-118, 2012.

BRASIL. Ministério da Integração Nacional. Secretaria de Infra-Estrutura Hídrica. Unidade de Gerenciamento do Proágua/semiárido. Diretrizes ambientais para projeto e construção de barragens e operação de reservatórios. Brasília: Bárbara Bela Editora Gráfica e Papelaria Ltda. 2005.

ESTEVES, F. de A. Fundamentos de Limnologia. 2 ed. Rio de Janeiro: Interciência, 575 p. 1998.

Fundamentos de Limnologia. $3^{\mathrm{a}}$ ed. Rio de Janeiro: Interciência. 790 p. 2011, 


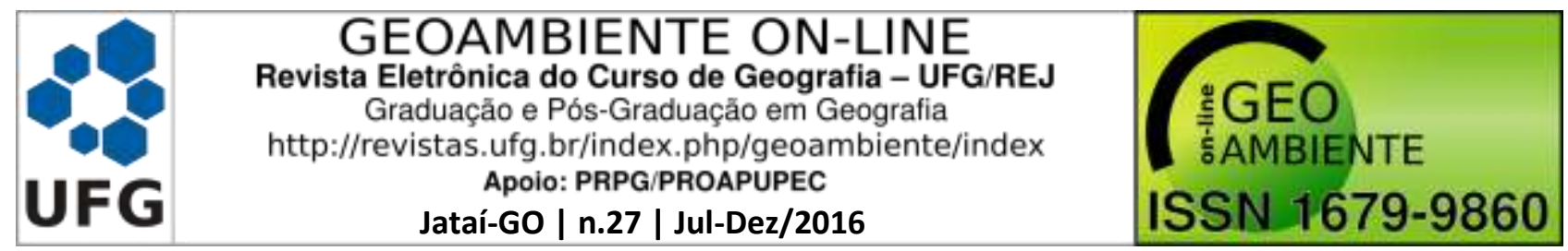

FONTES, A. S.; OLIVEIRA, J. I. R.; MEDEIROS, Y. D. P. A evaporação em açudes no semiárido nordestino do Brasil e a Gestão das águas. IN: XV Simpósio Brasileiro de Recursos Hídricos, Curitiba (PR), Anais... Curitiba: ABRH. p. 1-19. 2003.

GONDIM-FILHO, J. G. C.; FRANCA, D. T.; FORMIGA, K. T. M. Programa de Abastecimento da População Rural Difusa da região Semi-Árida: estudo técnico de apoio ao PBHSF, no 11. ANA/GEF/PNUMA/OEA, Brasília, 2004.

IBGE. Instituto Brasileiro de Geografia e Estatística. Manual técnico de uso da Terra. 2. ed. Rio de Janeiro, 91 p. 2006.

MALVEZZI, R. Semiárido: uma visão holística. Brasília: Confea. 140 p. 2007.

MALTCHIK, L.; DUARTE, M.D.C.; BARRETO, A.P. Resistance and resilience of periphyton to disturbance by flash floods in a Brazilian semiarid ephemeral stream (Riacho Serra Branca, NE, Brazil). IN: Anais da Academia Brasileira de Ciências, Rio de Janeiro. Anais... Rio de Janeiro: Academia Brasileira de Ciências, 1999.

MALTCHIK, L.; MEDEIROS, E.S.F. Conservation importance of semi-arid streams in northeastern Brazil: implications of hydrological disturbance and species diversity. Aquatic Conservation: Marine and Freshwater Ecosystems, v. 16, n. 7, p. 665-677, 2006.

MARTINS, E. S. P. R.; MENESCAL, R. A.; WARREN, M. SCHERER.; CARVALHO, M. S. B. S.; MELO, M. S.; PERINI, D. S.; OLIVEIRA, F. A. J. de. Utilização de imagens CBERS para mapeamento dos espelhos d'água do Brasil. IN: XIII Simpósio Brasileiro de Sensoriamento Remoto, Florianópolis, Anais... Florianópolis : INPE, 21-26 abril, 2007.

MENDONÇA, F.; DANNI-OLIVEIRA, I. M. Climatologia: noções básicas e climas do Brasil. São Paulo: Oficina de Textos. 206 p. 2007.

MIXON, D. M.; KINNER, D. A.; STALLARD, R. F.; SYVITSKI, J. P.M. Geolocation of man-made reservoirs across terrains of varying complexity using GIS. Computers \& Geosciences, v. 34, p. 1184-1197, 2008.

QUEIROZ, A.T.; OLIVEIRA, L. A. Relação entre produção e demanda hídrica na Bacia do Rio Uberabinha, Estado de Minas Gerais, Brasil. Revista Sociedade \& Natureza, Uberlândia, v. 1, n. 25, p. 191-204, 2013.

SANTANA, M. O. Atlas de áreas susceptíveis à desertificação no Brasil. Brasília/DF: Ministério do Meio Ambiente. 134 p. 2007.

SETTI, A. A.; LIMA J. E. F. W.; CHAVES, A. G. M.; PEREIRA, I. C. Introdução ao Gerenciamento de Recursos Hídricos. 2a ed. Brasília, ANEEL/ANA. 327 p. 2001. 


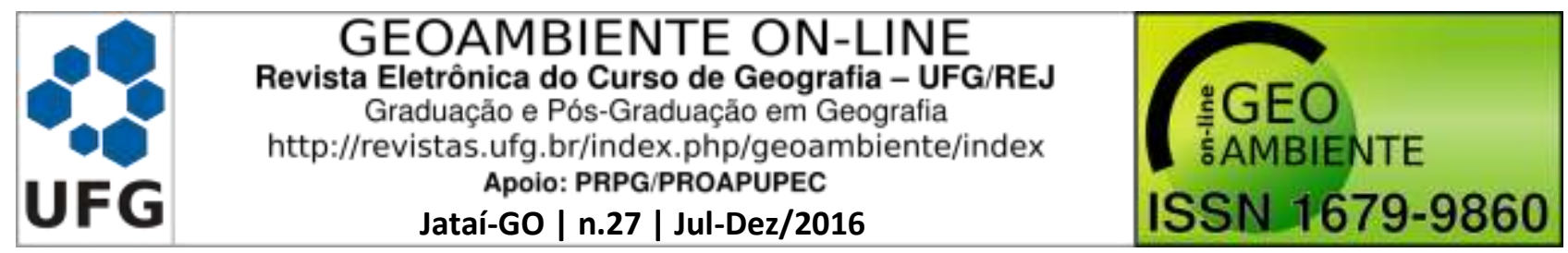

SUASSUNA, J. A pequena e média açudagem no semiárido nordestino: uso da água na produção de alimentos. Disponível em: 〈http://www.fundaj.gov.br/docs/text/textrop.html>. Acesso em: 10 Junho de 2014.

TUNDISI, J. G; MATSUMURA-TUNDISI, T. Limnologia. São Paulo: Oficina de Textos. 631 p. 2008.

TUNDISI, J. G.; MATSUMURA-TUNDISI, T. —The Lobo-Broa: Ecosystem Research In: TUNDISI, J. G.; BICUDO, C. E. M.; MATSUMURA-TUNDISI, T. (Eds.). Limnology in Brazil. Brazilian Academy of Sciences, Brazilian Limnological Society, p. 219-244. 1995. VAN TY, T.; BABEL, M. S.; SUNADA, K. OISHI, S.; KAWASAKI, A. Utilization of a GIS-Based Water Infrastructure Inventory for Water Resources Assessment at Local Level: A Case Study in Mountainous Area of Vietnam. Hydrological Research, n. 3, p. 27-31, 2009. 